\title{
Stage II Testicular Cancer AJCC v8
}

National Cancer Institute

\section{Source}

National Cancer Institute. Stage /I Testicular Cancer A/CC v8. NCI Thesaurus. Code C140233.

Stage II includes: Any PT/TX, N1-3, M0, SX. TX: Testicular cancer in which the primary tumor cannot be assessed. N1: Testicular cancer with metastasis with a lymph node mass $2 \mathrm{~cm}$ or smaller in greatest dimension and less than or equal to five nodes positive, none larger than $2 \mathrm{~cm}$ in greatest dimension. N2: T esticular cancer with metastasis with a lymph node mass larger than $2 \mathrm{~cm}$ but not larger than $5 \mathrm{~cm}$ in greatest dimension; or more than five nodes positive, none larger than $5 \mathrm{~cm}$; or evidence of extranodal extension of tumor. N3: Testicular cancer with metastasis with a lymph node mass larger than $5 \mathrm{~cm}$ in greatest dimension. M0: Testicular cancer without evidence of distant metastasis. SX: Marker studies not available or not performed. (AJCC 8th ed.) 